\title{
A model study on the influence of overshooting convection on TTL water vapour
}

\author{
M. E. E. Hassim and T. P. Lane \\ School of Earth Sciences, The University of Melbourne, Melbourne, Victoria 3010, Australia \\ Received: 22 April 2010 - Published in Atmos. Chem. Phys. Discuss.: 9 July 2010 \\ Revised: 27 September 2010 - Accepted: 13 October 2010 - Published: 19 October 2010
}

\begin{abstract}
Overshooting deep convection that penetrates into the Tropical Tropopause Layer (TTL) is thought to have an important role in regulating the water vapour content of this region. Yet, the net effect of such convection and the dominant mechanisms remain unclear. This study uses two idealised three-dimensional cloud-resolving model simulations to examine the influence of overshooting convection on water vapour when it penetrates into two different TTL environments, one supersaturated and the other subsaturated with respect to ice. These simulations show that the overshooting convection plays a direct role in driving the ambient environment towards ice saturation through either net moistening (subsaturated TTL) or net dehydration (supersaturated TTL). Moreover, in these cases the extent of dehydration in supersaturated conditions is greater than the moistening in subsaturated conditions. With the aid of modelled passive tracers, the relative roles of transport, mixing and ice microphysics are assessed; ultimately, ice sublimation and scavenging processes play the most important role in defining the different TTL relative humidity tendencies. In addition, significant moistening in both cases is modelled well into the subsaturated tropical lower stratosphere (up to $450 \mathrm{~K}$ ), even though the overshooting turrets only reach approximately $420 \mathrm{~K}$. It is shown that this moistening is the result of jumping cirrus, which is induced by the localised upward transport and mixing of TTL air following the collapse of the overshooting turret.
\end{abstract}

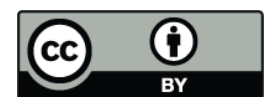

Correspondence to: M. Hassim (m.hassim1@pgrad.unimelb.edu.au)

\section{Introduction}

The transition from the convectively-driven troposphere to the radiatively-driven stratosphere in the tropics occurs gradually over an atmospheric layer several kilometres deep. This layer has been termed the Tropical Tropopause Layer (TTL, Sherwood and Dessler, 2000, 2001) and it is usually regarded as the source region for most of the air entering into the stratosphere (Gettelman and Birner, 2007; Fueglistaler et al., 2009). In recent years, physical and dynamical processes occurring within the TTL have attracted considerable attention, in part motivated by the need to better understand the mechanisms controlling the water vapour content of the stratosphere.

One important process in the TTL is overshooting deep convection (i.e. moist convection that exceeds its level of neutral buoyancy, LNB). At present, the contribution of overshooting deep convection to stratospheric humidity is still undergoing debate. Previous theoretical considerations and observational findings have argued that overshooting convection penetrating into the TTL (hereafter defined as the region between approx. $14-18.5 \mathrm{~km}$ altitude, the $150-50 \mathrm{hPa}$ pressure levels, or the 355-425 K isentropic surfaces following Fueglistaler et al., 2009) has a net dehydrating effect caused by the irreversible mixing of colder, drier air into the ambient environment (Danielsen, 1982, 1993; Russell et al., 1993; Sherwood and Dessler, 2000, 2001). More recently however, Corti et al. (2008), Khaykin et al. (2009) and de Reus et al. (2009), along with several modelling studies (e.g., Grosvenor et al., 2007; Chaboureau et al., 2007; Chemel et al., 2009) have suggested that such intense convection, particularly those systems that reach the lowermost tropical stratosphere (potential temperature, $\theta>385 \mathrm{~K}$ ), tended to have a moistening effect instead due to the injection of ice mass. They argued that strong overshooting updrafts transport most of their total water content (sum of vapour and ice phases) as ice,

Published by Copernicus Publications on behalf of the European Geosciences Union. 
which tends to evaporate/sublimate after these turrets collapse. Using radiometer measurements from the Microwave Limb Sounder instrument, Wu et al. (2005) have shown that convectively-injected ice can contribute significantly to the total water content near the tropical cold point, suggesting the importance of convection that extends throughout the TTL.

While it seems obvious that overshooting deep convection plays an influential role in regulating the water content of the TTL, the dominant processes by which it affects water vapour remain somewhat elusive. In particular, the relative roles of transport, mixing and microphysical processes, along with the sensitivities of these processes to the ambient TTL relative humidity, are still unclear. Jensen et al. (2007) used a numerical model to investigate the dehydration potential of overshooting convection and concluded that in areas where the TTL is routinely penetrated by convection, the overall influence depends on the background relative humidity of the region. They found that if the initial TTL relative humidity with respect to ice (RHI) was subsaturated, then overshooting convection would moisten the surrounding environment; conversely, if the TTL was initially supersaturated, then the injected ice would grow and deplete the TTL water vapour content. Given that on a global scale, overshooting events are occurring more frequently (in preferred regions and seasons) than previously thought (Schmetz et al., 1997; Alcala and Dessler, 2002; Liu and Zipser, 2005; Dessler et al., 2006; Zipser et al., 2006; Rossow and Pearl, 2007), it is important to understand specifically how individual overshooting convective clouds affect the water content of the tropical upper-troposphere/lower-stratosphere (UTLS) region. Thus, the aim of this study is to better understand the mechanisms that govern the impact of overshooting convection on TTL water vapour locally.

In this study, results from two idealised three-dimensional (3-D) cloud-resolving model simulations of overshooting deep convection are presented. These simulations are initialised with environments guided by soundings obtained from the recent Tropical Warm Pool-International Cloud Experiment (TWP-ICE) conducted in Darwin, Australia during the monsoon period over January-February of 2006 (May et al., 2008). The two chosen environments represent subsaturated and supersaturated TTL RHI conditions, respectively. These differences allow the influence of background TTL conditions in governing the net effect of overshooting convection on the TTL water budget to be evaluated. In order to assess the role of vertical transport, passive tracers are also incorporated into the model as proxies for parcel origin.

The remainder of the paper is organised as follows: Sect. 2 describes the model configurations used in this study. Results from the two simulations of overshooting convection are presented in Sect. 3, along with a discussion of the relative roles of microphysics, transport and mixing within the TTL. In Sect. 4, the modelled moistening above the TTL is also investigated. Finally, Sect. 5 presents a summary and the conclusions.

\section{Model description and case initialisations}

\subsection{Model settings}

This study employs the Weather Research and Forecasting (WRF) model (Advanced Research core version 2.2). In brief, the model solves the fully compressible, nonhydrostatic Euler equations (in flux form) on a staggered Arakawa C-grid, using a third-order accurate Runge-Kutta time-integration scheme and a mass-based (hydrostatic pressure) vertical coordinate. A full description of specific model details can be found in Skamarock et al. (2005). Because of its nonhydrostatic formulation, the WRF model is suitable for simulations that require grid spacings on the order of $250-1000 \mathrm{~m}$ to explicitly represent convection and clouds.

In this study, each simulation is computed inside a $160 \mathrm{~km} \times 160 \mathrm{~km}$ domain that is $30 \mathrm{~km}$ deep. Periodic boundary conditions are specified for both the $x$ - and $y$-directions. A horizontally-uniform $1 \mathrm{~km}$ grid spacing is used and the domain has 160 vertical levels. The vertical grid spacing ranges from an average of $0.15 \mathrm{~km}$ in the troposphere and the TTL region, to $0.28 \mathrm{~km}$ by $22 \mathrm{~km}$, before increasing exponentially to $0.75 \mathrm{~km}$ near the model top. These spatial dimensions are necessary to ensure that both convective-scale dynamics and convectively-generated gravity waves are adequately resolved although many unresolved turbulent processes still remain. A Rayleigh friction (sponge) layer is applied above $22 \mathrm{~km}$ to reduce the reflection of gravity waves from the uppermost boundary. The model uses 5th-order accurate horizontal differencing and 4th-order accurate vertical differencing for the advection of all variables.

While numerous physics options are offered within the WRF framework, the idealised numerical experiments performed here are configured with simplified model physics to clarify the interpretation of model results and allow for direct comparisons between the two cases. In particular, no radiation, boundary or surface layer schemes are used and convection in each case is initiated using a localised thermal perturbation of $3 \mathrm{~K}$ positioned near the surface and in the horizontal centre of the model domain. Coriolis effects are also excluded from the simulations. Cloud microphysical processes are parameterised using an updated version of the Thompson bulk microphysics scheme that implements a new snow parameterisation (Thompson et al., 2008). The effects of subgrid-scale mixing are parameterised using a 1.5 order turbulence kinetic energy (TKE) closure. Each case is integrated for a total of 6 model hours with a 3-s timestep.

The Thompson scheme is a relatively new microphysics parameterisation scheme that is under continuous development and testing. While being a bulk microphysics scheme, it has adopted several computational techniques to imitate some processes usually found in more sophisticated spectral bin microphysics schemes via the use of look-up tables. The Thompson scheme consists of six prognostic species, explicitly predicting the mixing ratios of water vapour, cloud water, 
rain, cloud ice, snow and graupel. In addition, the scheme also predicts the number concentration of cloud ice. Being a double-moment species, cloud ice has differential sedimentation according to the mixing ratio and number concentration by virtue of its respective mass-weighted and numberweighted terminal velocities (Thompson et al., 2008). The cloud droplet number concentration that gets nucleated at cloud base is defined by the default value of $100 \mathrm{~cm}^{-3}$. This value, intended as a proxy for initial aerosol content, is comparable to that of relatively clean air found above the planetary boundary layer or of maritime origin (Brock et al., 2004; Thompson et al., 2008).

The initial simulations using the default Thompson scheme (not shown) produced unexpected results near the cold-point region of the TTL. An examination of the microphysical code revealed that the formulation for saturation vapour pressure (with respect to ice; $e_{\text {ice}}$ ) did not account for temperatures below $-80^{\circ} \mathrm{C}$. However, these low temperatures were consistently observed during both the SCOUTO3/ACTIVE campaigns (Brunner et al., 2009; Vaughan et al., 2008) and also during TWP-ICE (Fig. 1b). Recently, Murphy and Koop (2005) conducted a comprehensive review of all the main formulations currently in meteorological use for calculating $e_{\text {ice }}$ and that for liquid/supercooled water, $e_{\mathrm{sw}}$. They concluded that all of the current $e_{\mathrm{sw}}$ expressions in popular use are "extrapolations that were not originally intended for use below the freezing point" (Murphy and Koop, 2005). Using new laboratory data on the molar heat capacity of supercooled water as constraints, they formulated a new expression for the vapour pressure over (hexagonal) ice, which presented a much better fit to selected experimental data that were the basis for previous formulations (Fig. 2 of Murphy and Koop, 2005). Thus, to remedy the problems with the default Thompson scheme at cold temperatures $\left(T \leq-80^{\circ} \mathrm{C}\right)$, its expressions for $e_{\text {ice }}$ and $e_{\mathrm{sw}}$ are replaced by those from Murphy and Koop (2005). All results reported in this study are from simulations conducted with this modified Thompson scheme. Accordingly, all RHI values are calculated using the Murphy and Koop (2005) equation for $e_{\text {ice }}$.

\subsection{Background conditions}

To assess the sensitivity to either a subsaturated or supersaturated ambient TTL environment, two different background conditions are created for the model (Fig. 1). These two profiles are extracted from dry-bias corrected radiosonde data obtained during TWP-ICE. The first background (thermodynamic) state is derived from the 23:15 UTC 20 January 2006 Darwin (12.3 S, 130.8 E) sounding. The second case is created by blending the Darwin sounding below $11.5 \mathrm{~km}$ with the 02:15 UTC 12 February 2006 Mount Bundy (13.2 S, $131.1 \mathrm{E})$ sounding above $11.5 \mathrm{~km}$. (The same conditions below $11.5 \mathrm{~km}$ are used to ensure similar convective development.) These two sounding locations formed part of the radiosonde network that covered the perimeter of the TWP-
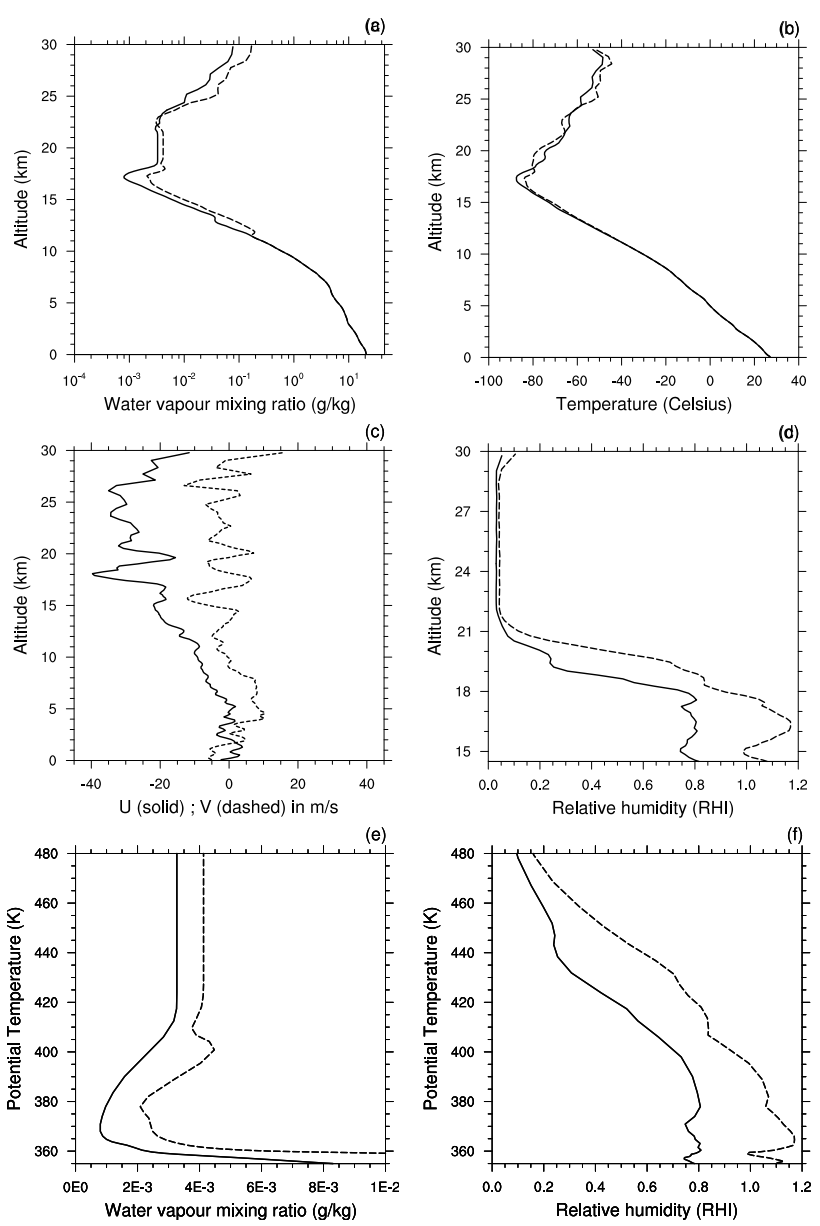

Fig. 1. Background profiles used to initialise the simulations. (a) water vapour, (b) temperature, (c) zonal (U) and meridional (V) wind, (d) relative humidity with respect to ice (RHI) versus altitude. (e) Water vapour and (f) RHI are versus potential temperature $(\theta)$ levels spanning $355-480 \mathrm{~K}$, corresponding to the altitude range of $\sim 14.5-20.5 \mathrm{~km}$. With the exception of (c), the solid lines correspond to profiles derived from the Darwin (SUBSAT) sounding and the dashed lines correspond to profiles derived from the Mount Bundy (SUPERSAT) sounding.

ICE domain centred around Darwin itself; Mount Bundy was the southernmost station, located approximately $90 \mathrm{~km}$ southeast of Darwin (see Fig. 1 of May et al., 2008). The two different profiles from the Darwin and Mount Bundy soundings provide subsaturated and supersaturated conditions (with respect to ice), respectively, within the TTL (Fig. 1d, f). In particular, the RHI difference between the two cases is maximised at approximately $16.5 \mathrm{~km}(\sim 365 \mathrm{~K})$, with a difference of almost $40 \%$, i.e. Darwin RHI is $\sim 80 \%$ and Mount Bundy RHI is $\sim 120 \%$ at that height. Supersaturated conditions extend up to the cold-point $(17.4 \mathrm{~km}, 380 \mathrm{~K})$ in the Mount Bundy case. For simplicity, we call the subsaturated TTL scenario the SUBSAT case and the supersaturated TTL scenario the SUPERSAT case. Note that the Darwin 

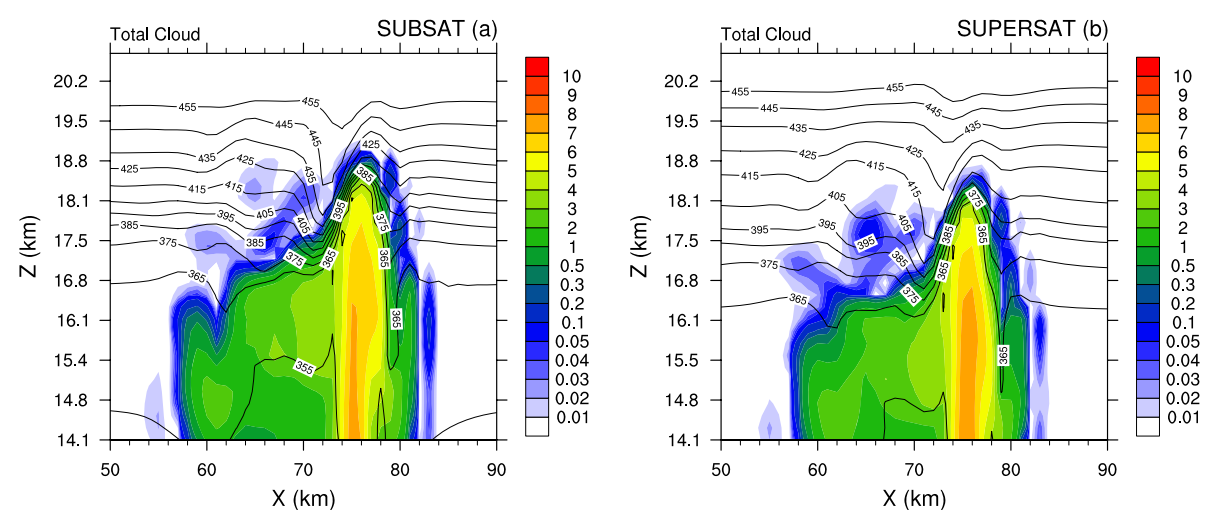

Fig. 2. Vertical cross-sections of total cloud mixing ratio $\left(\mathrm{g} \mathrm{kg}^{-1}\right)$ for (a) SUBSAT and (b) SUPERSAT, taken along $y=80 \mathrm{~km}$ at $t=40 \mathrm{~min}$. They show the TTL (and lower stratosphere) region only. Note that the levels of neutral buoyancy heights are 16.5 and $16.0 \mathrm{~km}$ for the SUBSAT and SUPERSAT cases, respectively.

sounding sampled the active/wet phase of the monsoon during TWP-ICE, while the Mount Bundy sounding sampled the break period of the monsoon. Such TTL RHI conditions are not necessarily typical of those generally observed for each convective regime and these soundings are chosen because they displayed two different upper-level RHI environments. Each case is also initialised with the same background wind profile extracted from the Darwin sounding (Fig. 1c), with the mean subtracted at all levels to maintain the simulated storms near the centre of the domain. Therefore, as both storms develop under the same upper-level wind conditions, the different storm behaviours (and their subsequent effects on TTL water content) are unlikely to be caused by wind shear.

Of course, it is quite possible that the observed RHIs used in this study suffer considerable instrument error. In particular, the reliability of temperature and water vapour measurements made by radiosonde sensors is reduced at upper-levels, since (among other things) the extremely cold temperatures encountered raises the likelihood of icing affecting the readings. While the RS92 radiosondes used throughout TWPICE have been corrected for their dry bias (Hume, personal communication), substantial uncertainties in the TTL RHI still remain. Nevertheless, the model is ignorant of the uncertainties in the background profiles, and the microphysics and dynamics evolve within those imposed initial states. Thus, the modelled TTL is initially supersaturated in SUPERSAT and subsaturated in SUBSAT, regardless of instrument uncertainty.

In each case, the raw thermodynamic profiles are smoothed and a constant water vapour mixing ratio is applied from approximately $19.0-21.5 \mathrm{~km}$ (Fig. 1a). These modifications are introduced to help mitigate any smoothing effects that implicit numerical diffusion might impose eventually on background structures with short vertical scales. In terms of their potential for deep convective development, the convective available potential energy of the two environ- ments are $3424 \mathrm{~J} \mathrm{~kg}^{-1}$ (SUBSAT) and $3208 \mathrm{~J} \mathrm{~kg}^{-1}$ (SUPERSAT). Moreover, both environments are similarly conducive to convection overshooting into the TTL with the LNB for the SUBSAT and SUPERSAT cases located at approximately 16.5 and $16.0 \mathrm{~km}$, respectively.

\subsection{Passive scalars}

To help separate the role of transport into the TTL by overshooting convection, two Eulerian passive scalars are incorporated in the model using the implementation described in Knievel et al. (2008). These scalars use the same numerical formulation as all other scalar variables in the model, including the same time step; they are therefore advected "online". In particular, an initial height scalar (IHGT, $\mathrm{km}$ ) and an initial water vapour mixing ratio scalar (IQV, $\mathrm{g} \mathrm{kg}^{-1}$ ) are introduced.

The IHGT and IQV scalars are initialised at each grid point on every level of the model domain with the corresponding values of geometric altitude and background water vapour mixing ratio, respectively. Therefore, profiles of both the IHGT and IQV scalars form a smooth and continuous distribution in the vertical, which serve to minimise numerical artifacts that may occur near sharp gradients (Wang et al., 2009a). In the absence of parameterised mixing, these scalar quantities are conserved and thus act as tracers to the flow and act as simple parcel origin proxies. By computing the perturbations of these scalar values at each grid point during each timestep, an indication of where the parcels have originated can be inferred from the sign and magnitude of the perturbation. 


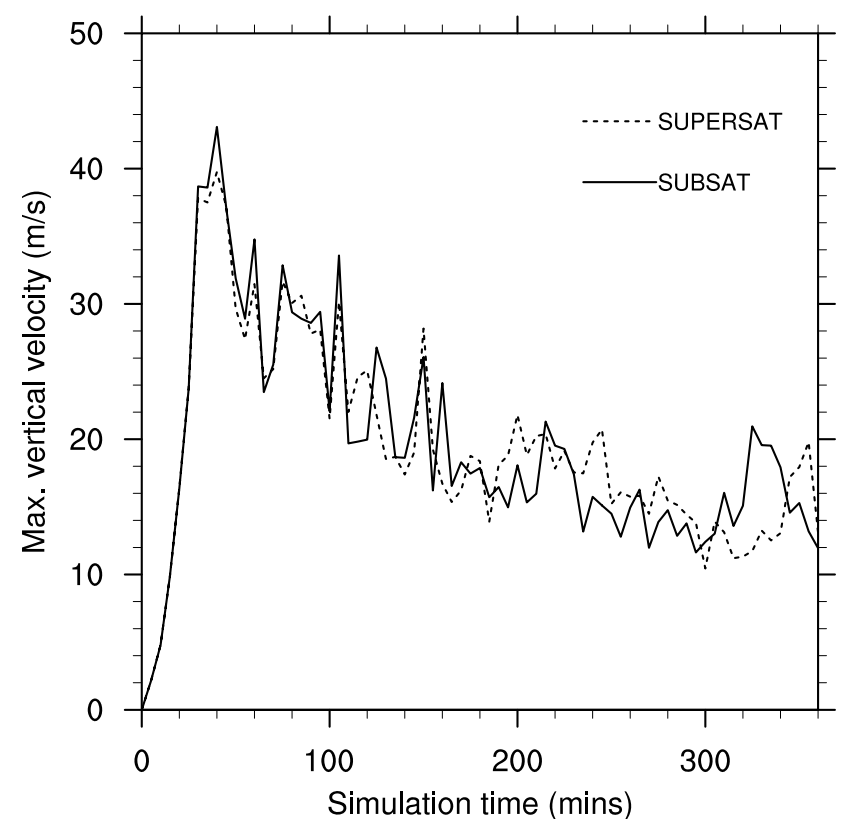

Fig. 3. Time series of maximum vertical velocity throughout the simulations.

\section{Results}

\subsection{Overview of simulations}

Using the same moisture and temperature profiles below $11.5 \mathrm{~km}$ means that the storms in the SUBSAT and SUPERSAT cases are initiated with the same thermodynamic conditions over a large extent of the troposphere and remarkably similar overshooting thunderstorms occur, albeit penetrating into two different TTL environments. In particular, vertical cross-sections of total cloud mixing ratio (sum of condensed water and ice) at the time of maximum overshoot (Fig. 2) indicate that, despite some minor differences in detail, there is a striking resemblance between the two storms. The systems have extremely similar structure and overshoot depth within the TTL. The vertical wind shear in the upper troposphere causes both storms to have a slightly tilted core updraft and horizontal asymmetry. Both modelled storms have overshot their LNB by at least $2 \mathrm{~km}$ (recall that the pre-convection SUBSAT and SUPERSAT LNBs are around $16.5 \mathrm{~km}$ and $16.0 \mathrm{~km}$ ), penetrating beyond each case's respective hygropause (level of minimum water vapour) and cold-point tropopause (level of minimum temperature) and into the lower stratosphere (see Fig. 1a, b). The first updraft penetrates the TTL after $30 \mathrm{~min}$ and approximately 10 min later maximum updraft speeds of approximately 43.1 and $39.7 \mathrm{~m} \mathrm{~s}^{-1}$ are achieved by the SUBSAT and SUPERSAT storms, respectively (Fig. 3). Furthermore, domainmaximum vertical velocities in excess of $10 \mathrm{~m} \mathrm{~s}^{-1}$ persist after the main convective overshooting episode, indicating that secondary convection is being generated for the remainder of the simulations.

Figure 4 shows horizontal cross-sections of the temperature perturbation and total water (vapour plus cloud water and ice species) for both cases at $40 \mathrm{~min}$ (the time of maximum overshoot) at $18 \mathrm{~km}$. Clearly evident are the signatures of overshooting convection; the cores of the overshooting turrets are much colder than their environment (perturbation magnitudes in excess of $20 \mathrm{~K}$, Fig. $4 \mathrm{a}$, b) and contain significant total water mixing ratio (Fig. 4c, d). Directly adjacent to the convective cores (in each case) are positive temperature perturbations associated with gravity waves (see also Fig. 2).

As shown by cross-sections of the IHGT tracer perturbation (Fig. 5), the air in the convective core at $18 \mathrm{~km}$ originates from the lower troposphere/boundary layer. In fact, the largest negative perturbations are in excess of $-15 \mathrm{~km}$, i.e. sourced from below $3 \mathrm{~km}$ altitude. This indicates that lowertropospheric air is rapidly advected from below into the TTL. Immediately encapsulating the largest negative IHGT perturbations, in the form of an annular outer shell $\sim 1 \mathrm{~km}$ thick (bluish-purple shades), are negative values ranging from -4 to $-12 \mathrm{~km}$. These represent mid-to-upper tropospheric and lower TTL air that have been entrained by the updraft. On the other hand, the gravity wave signatures adjacent to the core $(68<X<72 \mathrm{~km}, 76<Y<83 \mathrm{~km})$ possess positive IHGT perturbations less than a few kilometres, i.e. they indicate lower stratospheric and TTL air.

\subsection{Influence of overshoot on the background water vapour}

In this section, the evolution of the modelled TTL RHI and water vapour are presented for the two cases. Since the main intent of this study is to assess the role of overshooting convection on the TTL water vapour content, most of the analysis focuses on the outside of cloud; the cloud boundary is defined by a total cloud mixing ratio (cloud water plus ice species) of $0.01 \mathrm{~g} \mathrm{~kg}^{-1}$. Figure $6 \mathrm{a}, \mathrm{b}$ shows the vertical profile of out-of-cloud RHI, averaged on surfaces of constant potential temperature, for each case at 3 and $6 \mathrm{~h}$. The initial RHI profile is also shown for comparison. The profiles of perturbation RHI (from the initial state) are also presented (Fig. 6c, d) for every hour of the simulations.

Figure 6 shows that the two cases possess contrasting RHI tendencies in the TTL, with the net effect of the overshooting convection being to drive the TTL relative humidity towards (ice) saturation. The largest of the these RHI changes occur in the first $3 \mathrm{~h}$ (Fig. 6a, b). Net increases in average out-ofcloud RHI are modelled at levels where the TTL environment is initially subsaturated while reductions are simulated when the ambient TTL is supersaturated. This result is consistent with the interpretations of Dessler and Sherwood (2004), Smith et al. (2006) and Jensen et al. (2007). Moreover, the magnitude of maximum RHI decreases simulated in the SUPERSAT case are, on average, greater than the increases 

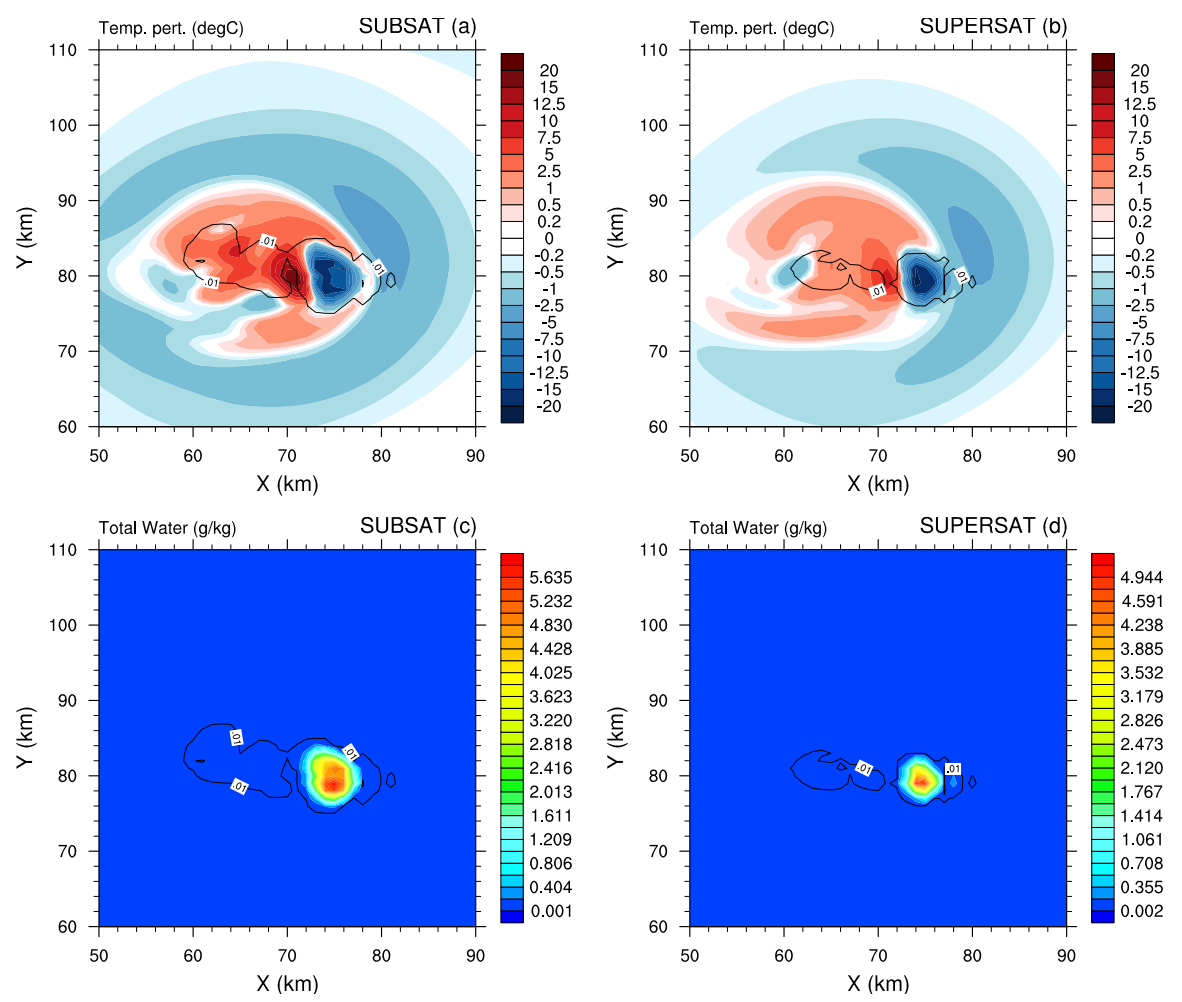

Fig. 4. Horizontal cross-sections at $18 \mathrm{~km}$ at $t=40 \mathrm{~min}$. (a) SUBSAT and (b) SUPERSAT perturbation temperature (Celsius), and (c) SUBSAT and (d) SUPERSAT total water mixing ratio $\left(\mathrm{g} \mathrm{kg}^{-1}\right)$. The black line indicates the $0.01 \mathrm{~g} \mathrm{~kg}^{-1}$ total cloud mixing ratio contour (marking the cloud boundary).
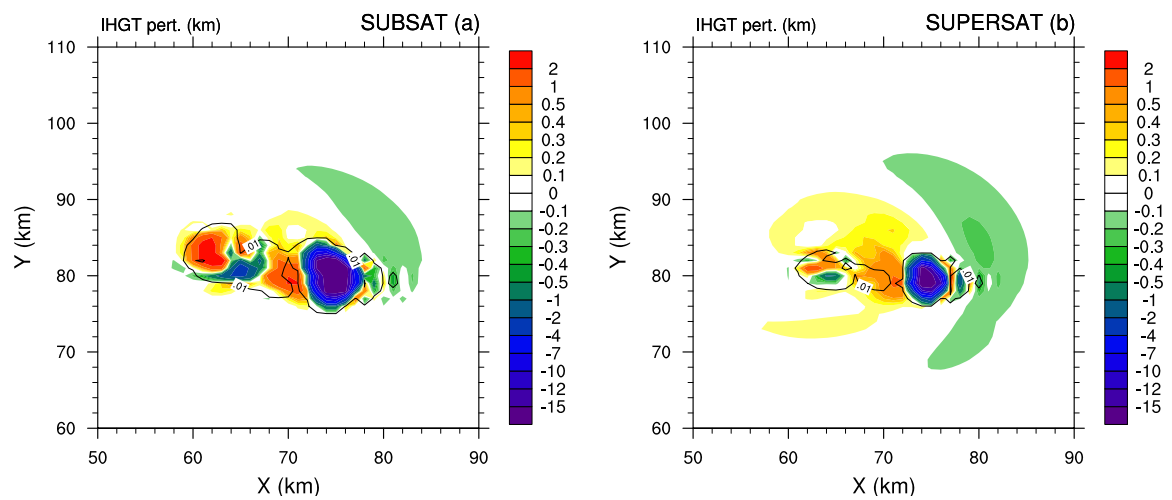

Fig. 5. Horizontal cross-section of IHGT tracer perturbation at $18 \mathrm{~km}$, at $t=40 \mathrm{~min}$ for (a) SUBSAT and (b) SUPERSAT. The black line represents the total cloud mixing ratio contour of $0.01 \mathrm{~g} \mathrm{~kg}^{-1}$ (marking the cloud boundary).

modelled for the SUBSAT case (e.g., at 360-375 K). An adjustment towards saturation has clearly occurred in both scenarios, but given that the initial deviations from saturation were comparable between the two cases (e.g. $\pm 20 \%$ in the lower TTL, defined as $355-385 \mathrm{~K}$ ), this effect is more pronounced in supersaturated TTL conditions (Fig. 6c, d).

Relative humidity (with respect to ice), by definition, is a function of both water vapour and temperature. Each of these variables are examined in Fig. 7 to determine which param- eter exerts the most influence on the modelled RHI differences in the lower TTL. Specifically, Fig. 7 shows perturbations from the initial state at $6 \mathrm{~h}$, vertically-averaged over the lower TTL for both SUBSAT and SUPERSAT cases. As both simulations present relatively similar spatial patterns and amplitudes of positive and negative temperature perturbations (Fig. 7a, b), it is clear that the modelled RHI differences between the two cases are being caused by diametrical changes in water vapour content (Fig. 7c, d). Moistening in the lower 

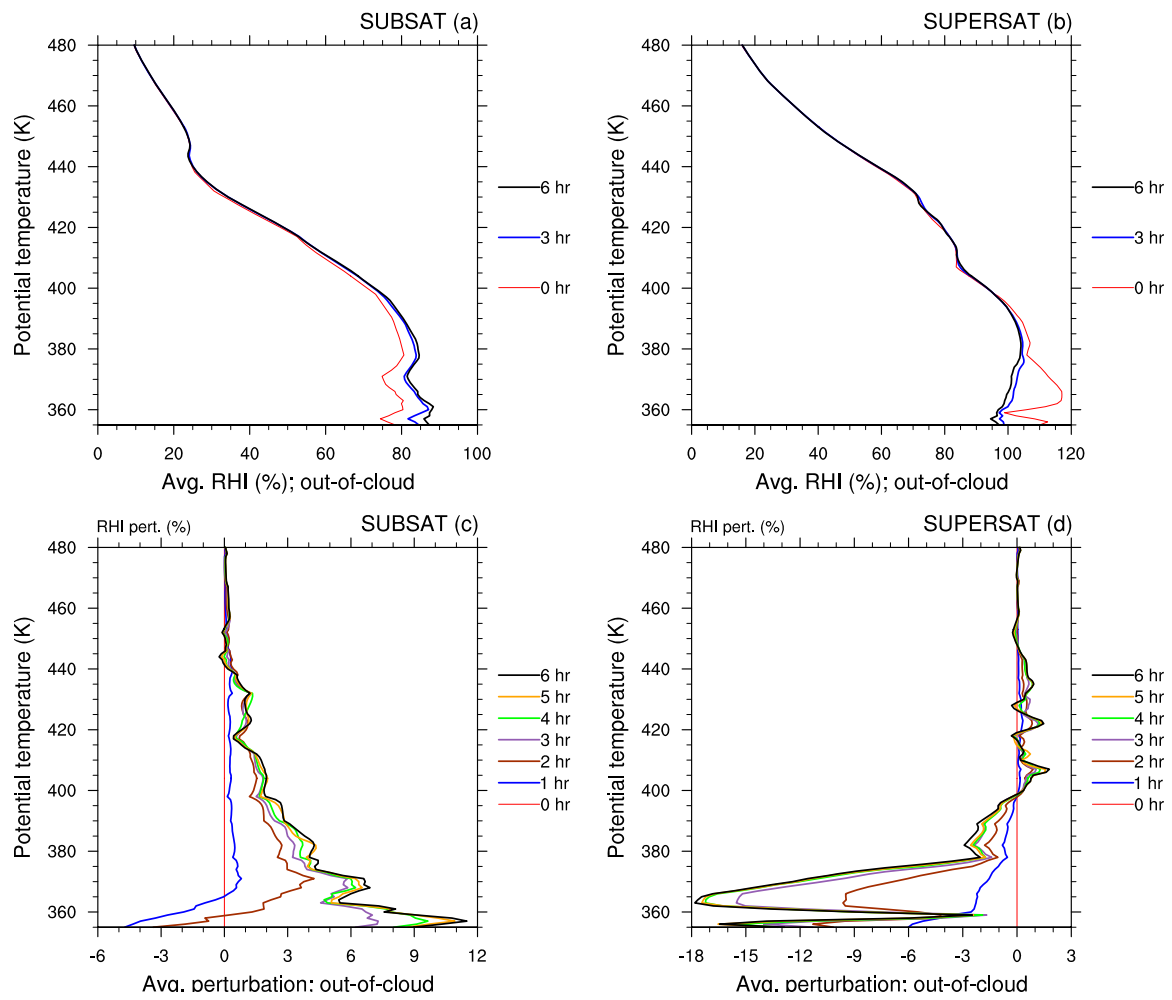

Fig. 6. Mean out-of-cloud RHI profiles at model times $t=0,3$ and $6 \mathrm{~h}$ for (a) SUBSAT and (b) SUPERSAT. The out-of-cloud RHI perturbations from the initial value for (c) SUBSAT and (d) SUPERSAT are also shown.

TTL has occurred in the SUBSAT case and net dehydration has occurred in the SUPERSAT case.

Note that the SUBSAT case produced an average net cooling of $\sim-0.15 \mathrm{~K}$ in the lower TTL (calculated using only the regions of negative temperature perturbations), which is only slightly greater in magnitude than the cooling in the SUPERSAT case $(\sim-0.11 \mathrm{~K})$. If anything, increased cooling would further reduce the water vapour mixing ratio and not increase it as is found in the SUBSAT case.

The evolution of the average out-of-cloud perturbations in water vapour, total water and total ice (sum of all ice species, hereafter referred to as simply ice unless otherwise specified), are examined in Fig. 8. (Note that technically, if ice is present, the air is inside cloud. Since the cloud boundary is defined as a total cloud mixing ratio of $0.01 \mathrm{~g} \mathrm{~kg}^{-1}$, the outof-cloud ice therefore has a lower concentration of mass.) At two hours, a considerable amount of ice is modelled up to $400 \mathrm{~K}$ in both cases, but its contribution to the changes in total water is different for each case. Specifically, most of the changes in SUBSAT total water (up to $400 \mathrm{~K}$ ) are explained by the presence of ice with only a small proportion accounted for by an increase in water vapour (Fig. 8a). Conversely, ice exceeds the SUPERSAT total water changes, which is partially compensated by substantial depletions in water vapour (Fig. 8b). This difference is noteworthy given that the magnitude and sign of total water changes are similar for both cases at this time. More ice is present in the SUPERSAT case between 360-370 K than in the SUBSAT case, which coincides with the TTL heights that were initially most supersaturated and where reductions in average water vapour are most pronounced. Also note that above $400 \mathrm{~K}$ in the SUBSAT case, there is an increase in total water that is almost entirely due to vapour increases. This moistening is present in both SUBSAT and SUPERSAT (but is more prominent in the SUBSAT case) and will be discussed in more detail in Sect. 4.

By $6 \mathrm{~h}$, the contribution of ice to the total water perturbations is reduced, with most changes in total water explained by water vapour. It is apparent that ice has been removed mostly through sedimentation. In the space of $4 \mathrm{~h}$, the magnitude of total water in the SUBSAT case, while still remaining positive, has decreased quite considerably. This reduction in magnitude is caused by the decrease in ice but compensated by the accompanying (small) increase in water vapour (Fig. 8c). In contrast, the sign of SUPERSAT total water perturbation has reversed below $400 \mathrm{~K}$. Most of the net total water depletion in the SUPERSAT case is now explained by the reduction in water vapour (Fig. 8d).

The above analysis suggests the important role of ice microphysics in the hydration/dehydration of the TTL by overshooting convection. In both cases, water is transported into the TTL, mostly in the form of ice. Once this ice is removed through sedimentation, the SUPERSAT case has sustained a 

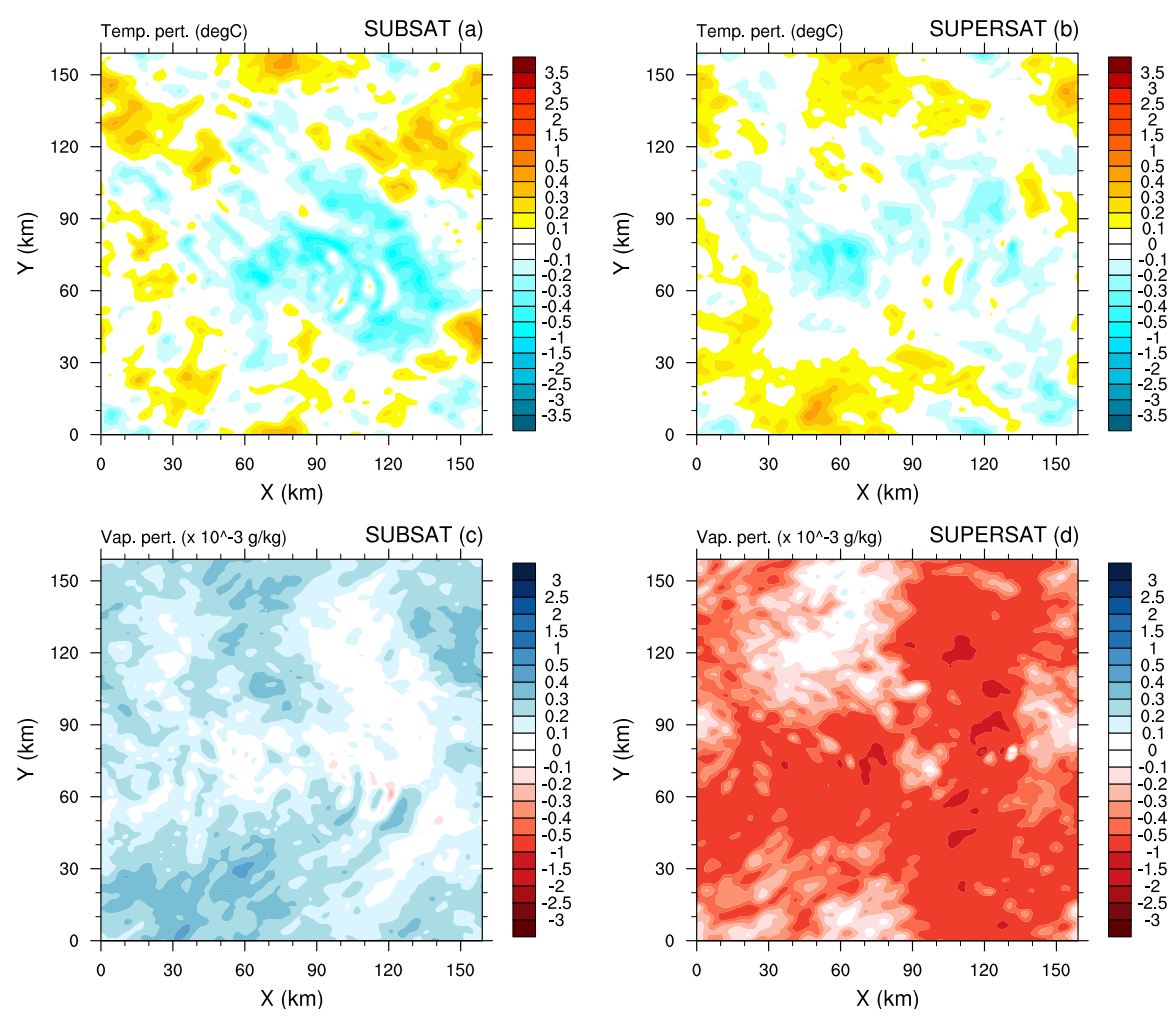

Fig. 7. SUBSAT and SUPERSAT horizontal cross-sections of $(\mathbf{a}, \mathbf{b})$ temperature perturbation and $(\mathbf{c}, \mathbf{d})$ water vapour perturbation, verticallyaveraged for the lower TTL portion $(355-385 \mathrm{~K})$ at $6 \mathrm{~h}$.

substantial loss of water vapour in the lower TTL. On the other hand, once the ice is removed in the SUBSAT case, there is a corresponding increase in water vapour. This result suggests the potential role of ice sublimation in moistening the TTL in the SUBSAT case and ice growth (scavenging) in dehydrating the TTL in the SUPERSAT case. The presence of ice in the TTL is ultimately linked to the amount of vertical transport, which is considered further in the next section.

\subsection{The role of transport}

As shown in the previous section, the vertical transport of water (ice and vapour) by overshooting convection plays an important role in determining the eventual TTL water vapour content. Thus, it is possible that the differences in TTL water vapour between SUBSAT and SUPERSAT are entirely due to differences in transport. Here, the modelled passive tracers are used to determine if any differences in transport are responsible for the different TTL RHI tendencies.

To compare the vertical transport of the two cases, hourly out-of-cloud profiles of domain-averaged IQV perturbations are presented in Fig. 9a, b. Also shown are the vertical cross-sections of IQV perturbations, taken at $y=75 \mathrm{~km}$ in each case, at $6 \mathrm{~h}$ (Fig. 9c, d). Recall, the IQV tracer is a conserved quantity (in the absence of parameterised mixing). It is not directly influenced by microphysical sources and sinks, and changes therefore indicate vertical displacements of air. Figure 9a, b shows that both cases exhibit very similar amounts of transport into the out-of-cloud TTL environment over time. The positive IQV perturbations in the TTL also highlight that, on average, a large proportion of the transport into the out-of-cloud environment has originated from below. This is further reflected in Fig. 9c, d, which shows that while some differences in detail are noticeable, the spatial patterns of positive and negative IQV perturbations are extremely similar. The IQV perturbations here and the IHGT perturbations shown in Fig. 5 show that lower tropospheric air is transported by overshooting convection into the TTL and supports the view that the lower TTL is highly convectively-influenced (Heyes et al., 2009; Schiller et al., 2009). Thus, because the convection evolves similarly in each case the differences in transport into the TTL are minor. This result implies that it is highly unlikely that the different TTL water vapour tendencies between SUBSAT and SUPERSAT are related to different transports, and more likely related to microphysical processes.

\subsection{Relative roles of microphysics, transport and mixing}

The results presented in the previous sections indicate that microphysical processes, related to the presence of 

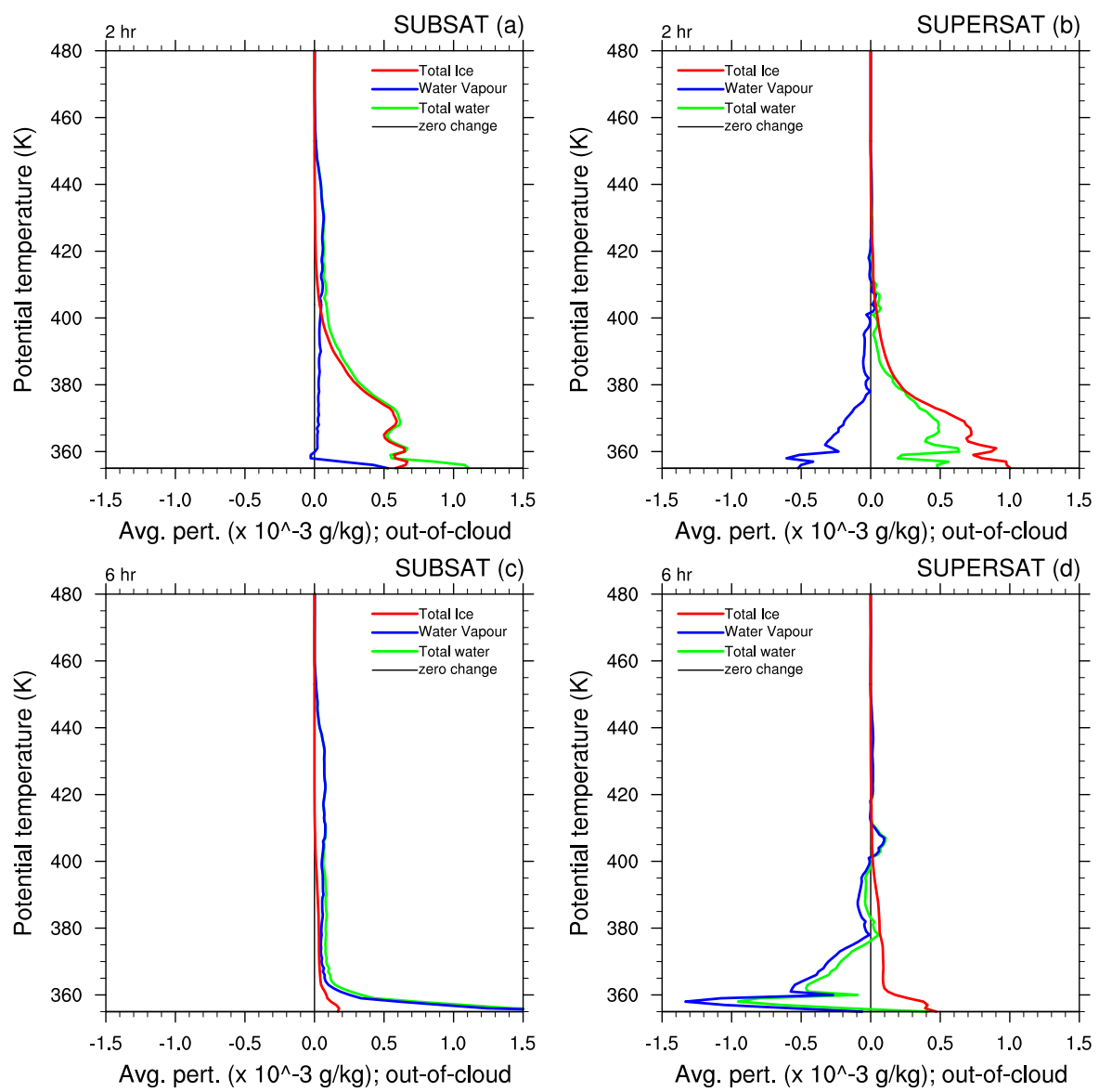

Fig. 8. Average out-of-cloud perturbations in total water (green), total ice (red) and water vapour (blue) content, plotted against $\theta$ levels $355-480 \mathrm{~K}$ for each case at $(\mathbf{a}, \mathbf{b}) 2 \mathrm{~h}$ and $(\mathbf{c}, \mathbf{d}) 6 \mathrm{~h}$.

(convectively-lofted) ice, are likely important for controlling the amount of moisture in the TTL. To consider this point further, Fig. 10 presents the time evolution of total water perturbation (from the initial state) for each case, taken as a vertical slice across three different sections of the domain at 2 , 4 and $6 \mathrm{~h}$, respectively. This is done following the general propagation of the storms in the negative $y$-direction. Parameterised mixing is also shown as stippled regions where TKE per unit mass exceeds $0.05 \mathrm{~m}^{2} \mathrm{~s}^{-2}$. This TKE threshold was chosen to simply indicate non-zero mixing, and best indicates the mixing within and near the cloud boundary (i.e. mixing due to interfacial instabilities.)

At two hours (Fig. 10a, b), the two cases are virtually indistinguishable exhibiting similar positive total water perturbations in the TTL that are largely due to the presence of a significant amount of lofted ice (cf. Fig. 8a, b). By four hours, disparities between the two cases have emerged in the lower TTL, and these become fully manifested at simulation end (Fig. 10e, f). Regions of negative total water perturbation denote those areas in which water vapour has been removed irreversibly, while positive regions indicate that moisture has been added and/or ice is still present. In particular, accompanying the sedimentation of ice out of the TTL, the water vapour mixing ratio of the SUBSAT case has increased on average in the TTL and decreased in the SUPERSAT case. Given that both cases display similar vertical transport (Figs. 9 and 10a, b), the differences in their respective TTL water vapour tendencies (both in sign and magnitude) reflect the dominant role of ice-phase microphysics in causing these tendencies.

The appearance of ice particles in a supersaturated layer serves to reduce the humidity rapidly, as ice would immediately grow by vapour deposition/diffusion at the expense of excess water vapour. When the ice eventually precipitates out, this leads to a permanent loss of moisture from that layer known as "scavenging". In the SUPERSAT case, scavenging occurs between 355 and $400 \mathrm{~K}$. The opposite effect is expected to occur when ice is introduced into a subsaturated environment; ice may sublimate, hence increasing the environmental humidity. This moistening potential ceases once ice falls out of the subsaturated environment. As shown here, the magnitude of the water vapour/RHI changes in the TTL 

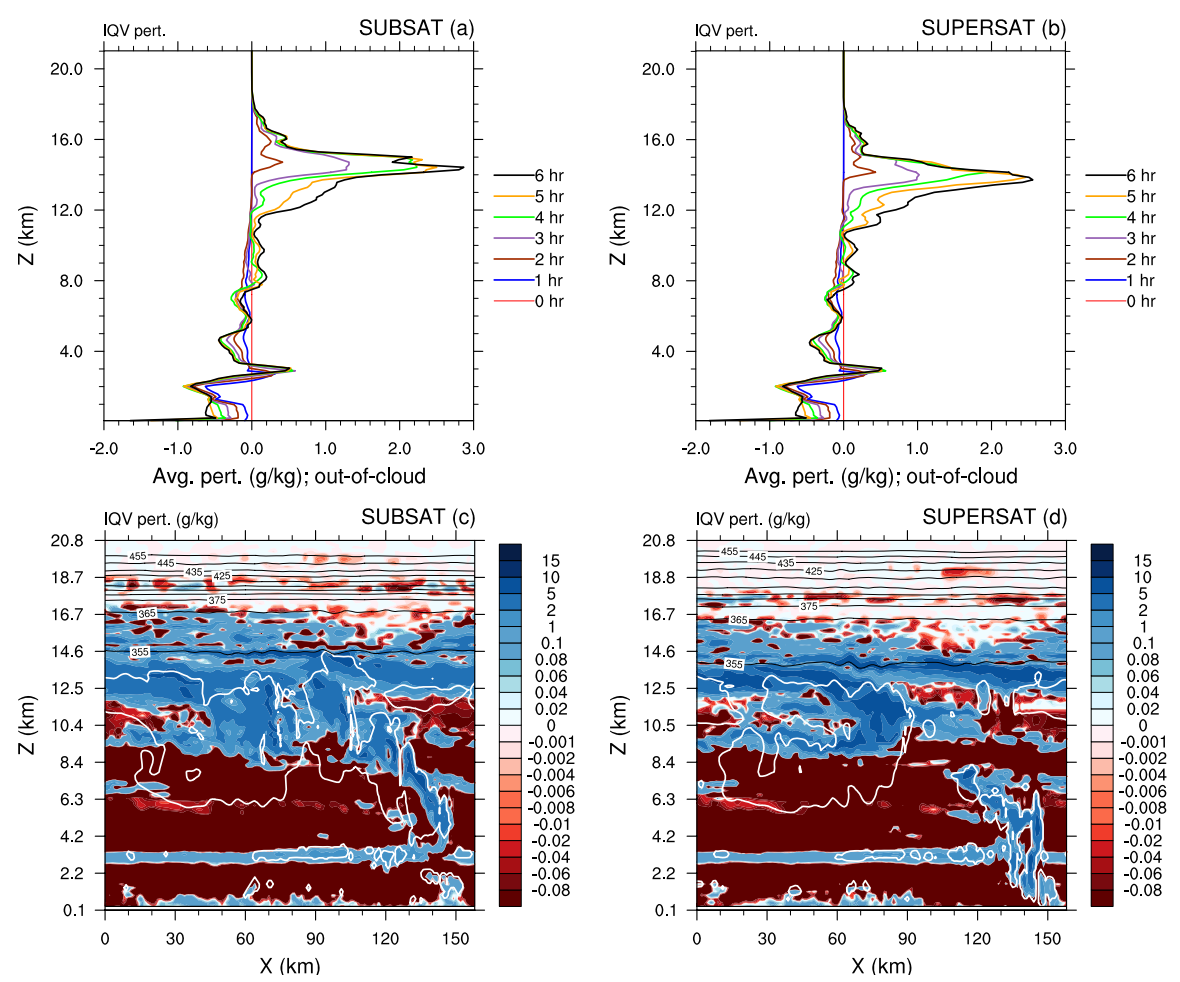

Fig. 9. IQV perturbation $\left(\mathrm{g} \mathrm{kg}^{-1}\right)$ for SUBSAT and SUPERSAT cases. (a, b) Average out-of-cloud profile. (c, d) Vertical cross-sections, taken at $y=75 \mathrm{~km}$ in each case, at $6 \mathrm{~h}$. The colour scale used in the vertical slices is not symmetric around zero, but chosen to reflect the logarithmic nature of water vapour content with height. The total cloud mixing ratio of $0.01 \mathrm{~g} \mathrm{~kg}^{-1}$ is also shown in white.

can be different for the two processes. The moistening due to sublimation ultimately relies on the mass of ice transported into the TTL, only a fraction of which will be sublimated before sedimentation out. On the other hand, the scavenging effect is related to the number of ice particles lofted into the TTL; the entire supersaturated region forms a reservoir for the growth of those particles. In this case, the scavenging process (in the SUPERSAT case) is more efficient than sublimation (in the SUBSAT case), especially given that transport of water vapour into the TTL from below likely contributes to the moistening in the SUBSAT case as well.

Furthermore, with the prescribed initial proxy aerosol concentration being low $\left(100 \mathrm{~cm}^{-3}\right)$, crystal concentrations in both cases would have been minimised while crystal sizes and hence fall speeds would have been maximised. Given a narrowed size distribution of the ice species involved, larger crystals will tend to precipitate out faster without the chance to fully sublimate; less ice is therefore available for moistening in the TTL. This probably explains why the average SUBSAT magnitude of net moisture gain in the lower TTL between 360 and $385 \mathrm{~K}$ did not increase appreciably throughout the remainder of its model run.

The results also imply that the role of ice-phase microphysics seems to prevail over the effects of small-scale mixing processes in the TTL. Such parameterised mixing could redistribute water vapour, leading to localised moistening or drying. Yet, as shown in Fig. 10, mixing in the TTL is much more localised than the extensive patterns of respective moistening or drying. There is also very little mixing outside of cloud. The average tendencies would likely be similar in both cases if mixing were playing an important role. Grosvenor et al. (2007) had attributed their modelled drying to the use of two dimensions and the lack of "realistic" mixing. The use of three dimensions here should produce a better representation of the mixing. Yet, the resolution of the model is still insufficient to properly represent entrainment and mixing processes.

During the simulations, snow was found to be the most abundant ice species produced, even in the vicinity of the overshooting turret (not shown). By design, this version of the Thompson scheme is in fact more tuned to the production of snow because cloud ice with particle diameters $>200 \mu \mathrm{m}$ gets automatically transferred to the snow category at each time step. To assess the relative importance of ice microphysics and sedimentation to the magnitude of overall modelled response, two further sensitivity runs were conducted in which the sedimentation velocity for snow was varied. For both the SUBSAT and SUPERSAT cases, the snow terminal velocity was doubled (for all sizes). Correspondingly, this reduced the potential for moistening by sublimation in 

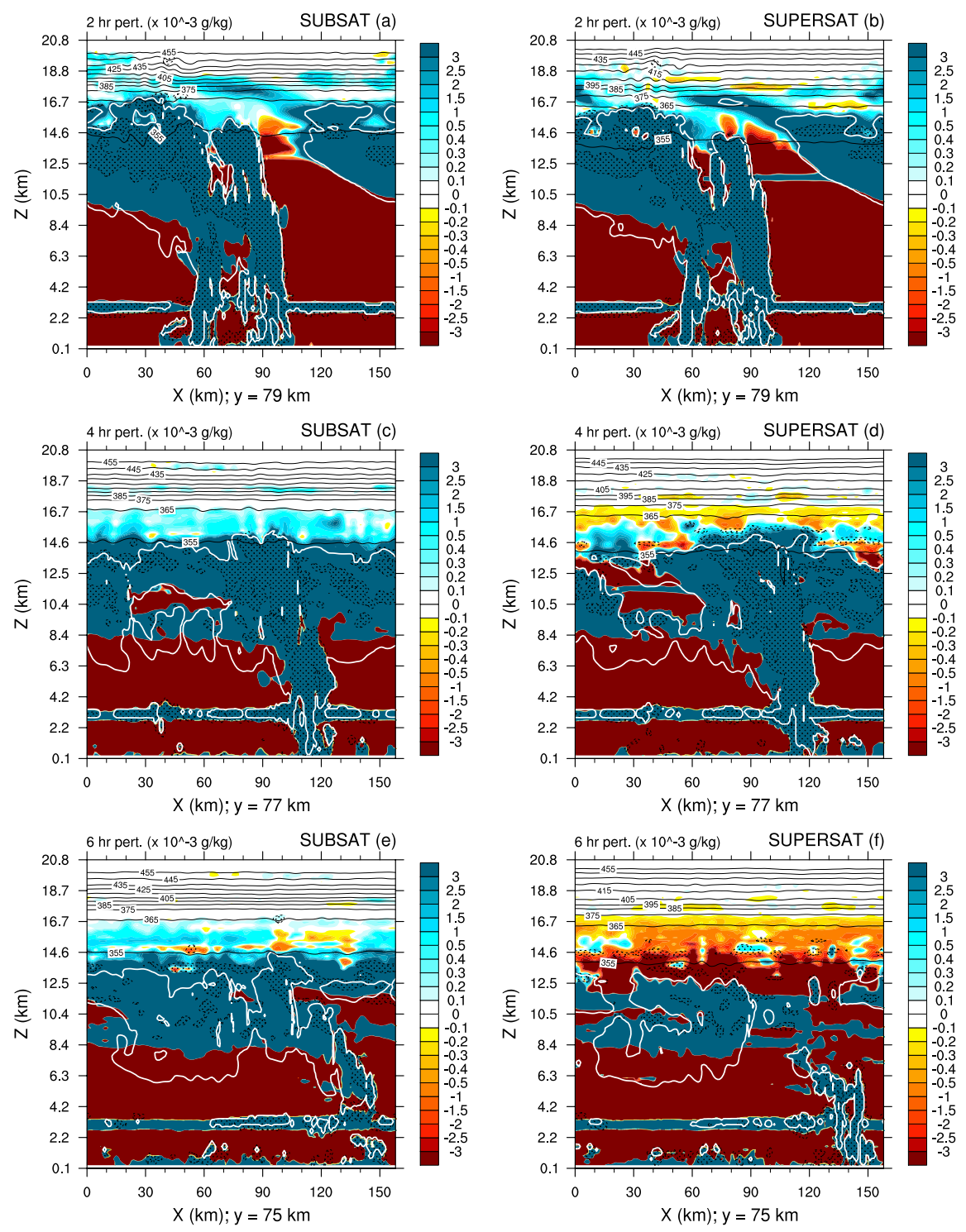

Fig. 10. Vertical cross-sections of total water perturbation for (a, c, e) SUBSAT and (b, d, f) SUPERSAT cases, taken at $2 \mathrm{~h}$ intervals along $y=79,77$ and $75 \mathrm{~km}$, respectively. Potential temperatures isolines, contoured every $10 \mathrm{~K}$ between $355-455 \mathrm{~K}$, are overlaid. The thick white line represents the total cloud mixing ratio of $0.01 \mathrm{~g} \mathrm{~kg}^{-1}$. Stippled regions correspond to where parameterised TKE per unit mass exceeds $0.05 \mathrm{~m}^{2} \mathrm{~s}^{-2}$ to indicate non-zero mixing within and near the cloud boundary.

the SUBSAT case and reduced the potential for dehydration through scavenging in the SUPERSAT case by allowing less time in the TTL. Overall results, however, were robust and very similar to that of the original simulations. Net moistening, particularly in the lower TTL, was still modelled in the SUBSAT case while net dehydration (of similar magnitudes) was again simulated in the SUPERSAT case (not shown). This demonstrates that, independently, both the "vapour-scavenging" and the "vapour-enrichment" effects of ice are sufficiently efficient and insensitive to variations in fallout velocity when ice is introduced into either a supersaturated or a subsaturated TTL environment. However, in a scheme with a tendency to produce less snow and more cloud ice, which has a much smaller fallout velocity, the outcomes may be different.

Finally, a number of other sensitivity tests were conducted (not shown). To ensure that the model would indeed maintain supersaturation in the TTL in the absence of lofted ice, the SUPERSAT model runs were repeated with progressively smaller initial thermal perturbations of $2.0,1.5,1.0,0.5$ and $0.2 \mathrm{~K}$. These indicated that when no convection reached the TTL (those experiments with $<1.0 \mathrm{~K}$ thermal perturbations), the initial supersaturated TTL was maintained. This was despite the fact that vertically-propagating gravity waves 


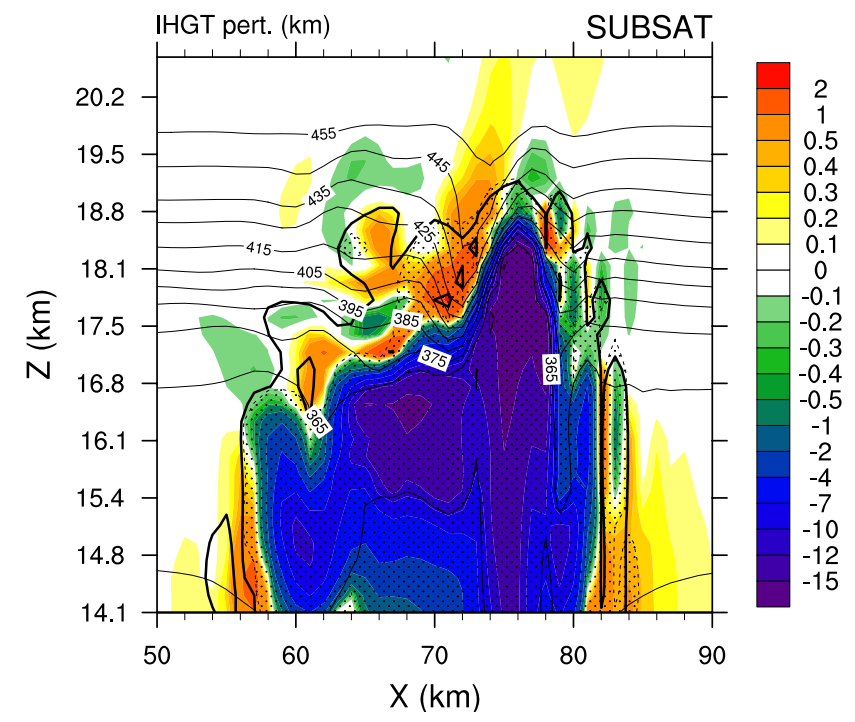

Fig. 11. Vertical cross-section of IHGT tracer perturbation for the SUBSAT case at $40 \mathrm{~min}$ (across $y=80 \mathrm{~km}$ ). Negative values indicate that parcels have originated from below while positive values indicate parcels from above. The thick black line represents the total cloud mixing ratio of $0.01 \mathrm{~g} \mathrm{~kg}^{-1}$ (and marks the cloud boundary). Potential temperature isolines, contoured every $10 \mathrm{~K}$ between 355 $455 \mathrm{~K}$, are overlaid. Stippled regions correspond to where parameterised TKE per unit mass exceeds $0.05 \mathrm{~m}^{2} \mathrm{~s}^{-2}$ to indicate non-zero mixing within and near the cloud boundary.

perturbed the TTL temperature significantly. However, it is possible that in these simulations, the temperature perturbations were insufficient for ice nucleation to occur. A simulation was also conducted in which the original Mount Bundy background profiles of moisture, temperature (below $11.5 \mathrm{~km}$ ) and wind were retained, thereby creating an entirely separate initial convective environment. While a characteristically different overshooting storm was produced in terms of structure and transport, the net TTL response after six model hours again mirrored that of the original SUPERSAT case. Therefore, the combined results of all the SUPERSAT sensitivity experiments further emphasises the importance of ice-phase scavenging in a given supersaturated TTL environment.

\section{Moistening beyond the TTL}

An additional feature of the simulations is the moistening beyond the upper limit of the TTL up to about $450 \mathrm{~K}$ $(\sim 19.8 \mathrm{~km})$. The degree of this moistening is largest in the SUBSAT case, showing increases of approximately $0.1 \times 10^{-3} \mathrm{~g} \mathrm{~kg}^{-1}(0.16 \mathrm{ppmv})$ on average. However, given that the overshooting updrafts only reached a maximum height of approximately $18.7 \mathrm{~km}$ (about $420 \mathrm{~K}$ ), this moistening further aloft cannot have been caused by direct injection of ice and/or water by the overshooting updraft. In this section, the mechanisms underlying this lower-stratospheric moistening are investigated using results from the SUBSAT case (which shows the most moistening).

Figure 11 shows that the convective overshoot induces a noticeable gravity wave, particularly in the region $(X \epsilon$ [70:75] km, $Z \geq 17.5 \mathrm{~km}$ ) immediately downwind (to the left) of the overshooting updraft core. As shown in Fig. 4a these wave perturbations are responsible for the downward displacement and adiabatic warming of stratospheric air directly adjacent to the updraft core and the upward displacement and cooling of TTL air surrounding the warming. These anomalies resemble the "cold-U/warm-centre" pattern more commonly identified in cloud-top brightness temperature imagery of intense thunderstorms or pyrocumulonimbus from space (Luderer et al., 2007). As shown by the IHGT tracer perturbations in Fig. 11 at the time of maximum overshoot, the steepening isentropes have drawn down higher stratospheric air (denoted by the orange shades) into the TTL on the downwind side of the turret. Significant volumes of parameterised turbulence occur in the vicinity of these wave perturbations. This mixing and turbulence is primarily caused by the steepening gravity wave, but other instabilities near the cloud boundary may also play a role (e.g. Lane et al., 2003; Lane and Sharman, 2006). The mixing provides a pathway for irreversible exchange of TTL air into the stratosphere.

Figure 12 presents a series of vertical cross-sections depicting the total water perturbation in the SUBSAT case, taken at $10 \mathrm{~min}$ intervals following the time of maximum cloud overshoot. As the overshooting turret decelerates and collapses due to the strong stratospheric stability gradient, a plume of ice and water vapour (blue shades) is seen to then emanate (Fig. $12 \mathrm{a} ; 60<X<70 \mathrm{~km}, 18.5<Z<19.8 \mathrm{~km}$ ) from the cloud top and then extend upstream from beyond the collapsed overshoot (Fig. 12c; $45<X<70 \mathrm{~km}$, $18.7<Z<19.8 \mathrm{~km}$ ). As the convection subsides (Fig. 12e), the plume (blue shades) remains above $425 \mathrm{~K}$, i.e. well above the top of the convective cloud $(35<X<65 \mathrm{~km}$, $18.7<Z<19.8 \mathrm{~km})$. The parameterised mixing is present throughout the evolution of the plume, facilitating an exchange of ice (and vapour) from within the cloud into the lower-stratospheric air. The eventual sublimation of this ice is likely responsible for the hydration above the TTL seen in Fig. 8a. The evolution of this water mass is extremely similar to the jumping cirrus phenomenon (Fujita, 1982) that has been explained by the numerical investigations of Wang $(2003,2004,2007)$ to be a result of the permanent, crossisentropic infusion of water vapour into the lower stratosphere by moisture plumes above deep mid-latitude storms.

Gravity wave breaking has been invoked as the primary mechanism responsible for the irreversible transport of water into the lower stratosphere by this phenomenon (Wang, 2004, 2007) and is the likely cause here. Wang (2003) suggested that the ice/moisture plume was of tropospheric origin, as it appeared to detach from the top of the main anvil that was 

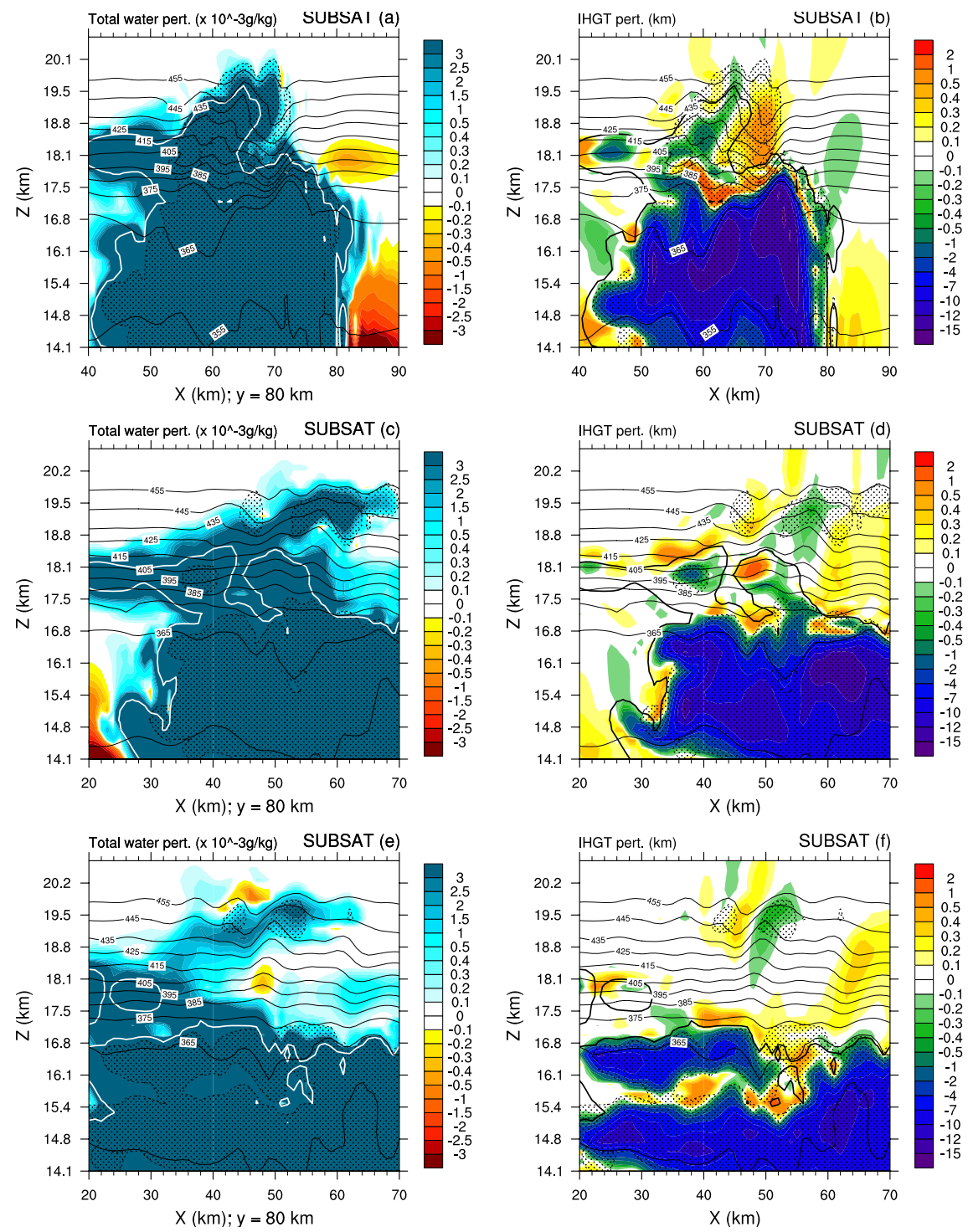

Fig. 12. Vertical cross-sections of total water and IHGT tracer perturbations in the SUBSAT case, taken at (a, b) $50 \mathrm{~min},(\mathbf{c}, \mathbf{d}) 60 \mathrm{~min}$ and (e, f) $70 \mathrm{~min}$, along $y=80 \mathrm{~km}$, following the time of maximum overshoot $(\mathrm{t}=40 \mathrm{~min})$. Potential temperatures isolines, contoured every $10 \mathrm{~K}$, are overlaid from $355-400 \mathrm{~K}$. Stippled regions correspond to where parameterised TKE per unit mass exceeds $0.05 \mathrm{~m}^{2} \mathrm{~s}-2$. The thick white or black line represents the total cloud mixing ratio of $0.01 \mathrm{~g} \mathrm{~kg}^{-1}$. Note that the horizontal locations of (a) and (b) are different to (c-f).

moving downstream of the collapsed overshoot. However, it was not clear whether the plume was composed of air parcels from the upper, middle or lower troposphere (including those from the boundary layer). Air from various heights will have different chemical signatures and convectively-lofted ice formed within those rapidly uplifted parcels would retain water isotope ratios characteristic of their source regions. Studies such as Moyer et al. (1996) and Hanisco et al. (2007) have demonstrated that the isotopic information derived from in-situ observations can be of conceptual benefit in assessing the degree of influence of overshooting convection on (lower) stratospheric water vapour, and it is therefore useful to determine exactly where the injected air is sourced from.
To investigate the origin of the jumping cirrus, Fig. 12 also presents the corresponding snapshots of IHGT tracer perturbations during 50-70 min of the SUBSAT simulation. At the location where the total water plume first forms, there are localised vertical displacements of air parcels of approximately $1 \mathrm{~km}$ in magnitude (Fig. 12b). As the plume evolves (Fig. 12d, f) and the convection subsides, both positive and negative IHGT perturbations remain. The presence of positive IHGT perturbations in the right portion of Fig. $12 \mathrm{f}$ (between 17 and $20 \mathrm{~km}$ ) indicate downward exchange of air from approximately $500 \mathrm{~m}$ aloft. In the region of the largest moisture perturbation $(Z=19.5 \mathrm{~km}, X=52 \mathrm{~km})$, i.e. the plume, the IHGT perturbation indicates the air is sourced 
from approximately $500-1000 \mathrm{~m}$ below. This suggests that the air within the plume is largely composed of existing TTL air that has been uplifted by several hundred metres (up to $1 \mathrm{~km})$. Hence, it is likely that a large proportion of the plume ice formed in-situ as the upper TTL parcels are uplifted. Turbulence, generated around the cloud (Lane et al., 2003; Lane and Sharman, 2006), would then mix the ice further aloft, eventually producing the enhanced water vapour beyond the TTL when the ice sublimated. Overall moistening has resulted simply because ice formed in-situ from the uplifted TTL parcels is mixed into a subsaturated environment at higher isentropic levels during the jumping process (Fig. 12d, f). Moreover, other simulations with tracers initially confined to the TTL, stratosphere and troposphere (not shown) also demonstrated that the plume is primarily of TTL origin.

Recent observational evidence presented by Setvák et al. (2008) and Wang et al. (2009b) suggests that these ice/moisture plumes are a common feature above overshooting thunderstorms whenever there is strong vertical wind shear, a condition known to favour gravity wave breaking (Lane et al., 2003). Certainly, in our cases, wind shear is present in the vicinity of the cold-point (Fig. 1c). Given a conducive dynamical environment, the process causing such plume occurrences constitutes a rapid tropospherestratosphere exchange mechanism. Note that a plume forming above the TTL (or above the cold-point tropopause) will most likely result in net moistening, as the tropical stratosphere at these altitudes is almost always subsaturated with respect to ice. On the other hand, if the plume (and the overshooting turret) occurred well below the cold-point but still within the TTL (e.g. between 14-16 km), then additional water vapour produced in the plume may not necessarily result in increased moisture transport into the lower stratosphere as this may be removed during subsequent radiative ascent (on the timescale of 20-30 days) through the cold-point. Hence in this regard, the role and importance of overshooting convection, relative to other transport pathways, in governing the moisture content beyond the TTL is dependent on the frequency and the altitudes of overshooting convection. Accordingly, the convective systems simulated here are characteristic of the deepest and most intense clouds in the maritime continent, and the results presented are likely an upper limit on the moistening potential of individual systems.

To this end, the total amount of water mass injected into the stratosphere beyond the TTL (i.e. $>425 \mathrm{~K}$ ) at the end of simulations is calculated to be approximately 118 tonnes in the SUBSAT case, and approximately 28 tonnes in the SUPERSAT case. Likewise, the total water mass injected into the stratospheric overworld $(>400 \mathrm{~K})$ in the SUBSAT case (at simulation end) amounts to approximately 298 tonnes, and for the SUPERSAT case, it is approximately 143 tonnes. Compared to a recent estimate (about 100 tonnes, Peter (2008)) that is based on a single, observed overshooting Hector event during the SCOUT-O3/ACTIVE campaigns, the cases herein likely provide an upper limit on the transport of water into the tropical lower stratosphere by the deepest and most intense individual systems.

\section{Summary and concluding remarks}

In this study, the Weather Research and Forecasting model has been used to conduct two three-dimensional, cloudresolving numerical simulations of idealised overshooting convection. By focusing on the out-of-cloud effects, the aim was to better understand the dominant physical processes that govern the role of overshooting convection in defining the TTL water content. The simulations were performed under idealised conditions with simplified model physics and initialised with soundings obtained from the Tropical Warm Pool-International Cloud Experiment (TWP-ICE, Darwin, Australia, 2006; May et al., 2008) that were specifically chosen to reflect subsaturated and supersaturated TTL conditions (with respect to ice) up to the observed tropical cold-point. In addition, the experiments were designed such that similar overshooting storms were produced, albeit penetrating into two different background TTL environments. These simplifications facilitated the interpretation of model results and allowed for direct comparisons between the two cases. To further aid the investigation, two passive scalars were incorporated into the model numerics as simple proxies for parcel origin in order to determine the relative importance of microphysics, transport and mixing by overshooting convection in influencing the localised TTL moisture tendencies for a given subsaturated or supersaturated environment.

Overall, the results demonstrated the dominant role of ice-phase microphysics in comparison to transport and mixing processes in governing TTL moisture tendencies locally, although the latter two processes are implicitly important. Specifically, it was shown that for the two cases (with indistinguishable transport of water into the TTL), the TTL water vapour content was depleted when the TTL was initially supersaturated and enhanced when the TTL was initially subsaturated. Hence, the process of convection penetrating the TTL acted to drive the environment towards ice saturation, agreeing with previous studies (e.g., Jensen et al., 2007; Grosvenor et al., 2007; Chemel et al., 2009). In addition, the humidity adjustment process was more efficient in supersaturated TTL conditions than in subsaturated conditions in these cases. The moistening of the subsaturated TTL was attributed to vertical transport of water vapour and ice that at least partially sublimated before sedimentation. Likewise, the dehydration of the TTL was attributed to "icescavenging"; where ice particles lofted into the TTL grow before sedimentation, hence depleting the TTL of moisture in the process. A substantial degree of moistening, particularly in the subsaturated TTL case, was also simulated beyond the TTL and well into the tropical lower stratosphere up to approximately $450 \mathrm{~K}$. This hydration was not caused by 
direct turret injection (the overshoots only reached altitudes of approx. $420 \mathrm{~K}$ ), but rather a result of jumping cirrus. The formation of this deep moisture plume was attributed to gravity wave breaking. Further, passive scalar analysis indicated that the source of the plume in our simulations was existing upper TTL air near the vicinity of the collapsed overshoot dome. These air parcels were found to be displaced upwards by up to $1 \mathrm{~km}$, immediately following the collapsed turret. Accordingly, these parcels and their ice content were irreversibly mixed with stratospheric air further aloft by the turbulence generated around the convective turret. Therefore, it was likely that a large fraction of the ice within the plume formed in the upper TTL, rather than being directly advected from much lower levels in the troposphere. Net hydration resulted because this ice was mixed into a subsaturated lower stratospheric environment.

Of course, the findings of this study are limited by the assumptions made in the model's microphysics parameterisations and its representation of turbulent mixing. Continued refinements of these representations, through improved computational resources and observational constraints, are crucial for ongoing progress. Nonetheless, the findings of this study suggest that overshooting deep convection plays a key role in driving the TTL towards ice saturation. Overshooting convection thereby provides the necessary catalyst for dehydration of the TTL/lower-stratosphere once it becomes supersaturated by horizontal transport (Holton and Gettelman, 2001; Gettelman et al., 2002) or other processes. The deepest and most intense clouds, such as those considered here, that penetrate the TTL have a direct influence; shallower convection may still influence the TTL through remote effects (e.g. gravity waves) and will be considered in future studies.

Acknowledgements. This research has been partially funded by the Australian Postgraduate Award, Australian Research Council's Discovery Projects (DP0770381) and Future Fellowships (FT0990892) schemes. The authors wish to thank Tim Hume (Australian Bureau of Meteorology) for providing the corrected TWP-ICE radiosonde data and Jason Knievel (NCAR) for supplying the code and instructions for the implementation of passive scalars in the WRF model. Thank you also to Andy Heymsfield (NCAR), Andrew Gettelman (NCAR), Greg Thompson (NCAR), Peter May (Centre for Australian Weather and Climate Research, CAWCR) and Kathrin Wapler (Deutscher Wetterdienst, DWD) for helpful discussions. Computing facilities were provided by the Victorian Partnership for Advanced Computing (VPAC). Finally, we would like to thank the two anonymous reviewers who helped improve the paper.

Edited by: P. Spichtinger

\section{References}

Alcala, C. M. and Dessler, A. E.: Observations of deep convection in the tropics using the TRMM precipitation radar, J. Geophys. Res., 107(D24), 4792, doi:10.1029/2002JD002457, 2002.

Brock, C. A., Hudson, P. K., Lovejoy, E. R., Sullivan, A., Nowak, J. B., Huey, L. G., Cooper, O. R., Cziczo, D. J., de Gouw, J., Fehsenfeld, F. C., Holloway, J. S., Hübler, G., Lafleur, B. G., Murphy, D. M., Neuman, J. A., D. K. Nicks Jr., Orsini, D. A., Parrish, D. D., Ryerson, T. B., Tanner, D. J., Warneke, C., Weber, R. J., and Wilson, J. C.: Particle characteristics following cloud-modified transport from Asia to North America, J. Geophys. Res., 109, D23S26, doi:10.1029/2003JD004198, 2004.

Brunner, D., Siegmund, P., May, P. T., Chappel, L., Schiller, C., Müller, R., Peter, T., Fueglistaler, S., MacKenzie, A. R., Fix, A., Schlager, H., Allen, G., Fjaeraa, A. M., Streibel, M., and Harris, N. R. P.: The SCOUT-O3 Darwin Aircraft Campaign: rationale and meteorology, Atmos. Chem. Phys., 9, 93-117, doi:10.5194/acp-9-93-2009, 2009.

Chaboureau, J.-P., Cammas, J.-P., Duron, J., Mascart, P. J., Sitnikov, N. M., and Voessing, H.-J.: A numerical study of tropical crosstropopause transport by convective overshoots, Atmos. Chem. Phys., 7, 1731-1740, doi:10.5194/acp-7-1731-2007, 2007.

Chemel, C., Russo, M. R., Pyle, J. A., Sokhi, R. S., and Schiller, C.: Quantifying the imprint of a severe hector thunderstorm during ACTIVE/SCOUT-O3 onto the water content in the upper troposphere/lower stratosphere, Mon. Weather Rev., 137, 2493-2514, doi:10.1175/2008MWR2666.1, 2009.

Corti, T., Luo, B. P., de Reus, M., Brunner, D., Cairo, F., Mahoney, M. J., Martucci, G., Matthey, R., Mitev, V., dos Santos, F. H., Schiller, C., Shur, G., Sitnikov, N. M., Spelten, N., Vössing, H. J., Borrmann, S., and Peter, T.: Unprecedented evidence for deep convection hydrating the tropical stratosphere, Geophys. Res. Lett., 35, L10810, doi:10.1029/2008GL033641, 2008.

Danielsen, E. F.: A dehydration mechanism for the stratosphere, Geophys. Res. Lett., 9, 605-608, 1982.

Danielsen, E. F.: In-situ evidence of rapid, vertical, irreversible transport of tropospheric air into the lower tropical stratosphere by convective cloud turrets and by larger-scale upwelling in tropical cyclones, J. Geophys. Res., 98, 8665-8681, 1993.

de Reus, M., Borrmann, S., Bansemer, A., Heymsfield, A. J., Weigel, R., Schiller, C., Mitev, V., Frey, W., Kunkel, D., Kürten, A., Curtius, J., Sitnikov, N. M., Ulanovsky, A., and Ravegnani, F.: Evidence for ice particles in the tropical stratosphere from in-situ measurements, Atmos. Chem. Phys., 9, 6775-6792, doi:10.5194/acp-9-6775-2009, 2009.

Dessler, A. E. and Sherwood, S. C.: Effect of convection on the summertime extratropical lower stratosphere, J. Geophys. Res., 109, D23301, doi:10.1029/2004JD005,209, 2004.

Dessler, A. E., Palm, S. P., and Spinhirne, J. D.: Tropical cloud-top height distributions revealed by the Ice, Cloud, and Land Elevation Satellite (ICESat)/Geoscience Laser Altimeter System (GLAS), J. Geophys. Res., 111, D12215, doi:10.1029/2005JD006,705, 2006.

Fueglistaler, S., Dessler, A. E., Dunkerton, T. J., Folkins, I., Fu, Q., and Mote, P. W.: Tropical Tropopause Layer, Rev. Geophys., 47, RG1004, doi:10.1029/2008RG000267, 2009.

Fujita, T. T.: Principle of stereographic height computations and 
their application to stratospheric cirrus over severe thunderstorms, J. Meteorol. Soc. Jpn., 60, 355-368, 1982.

Gettelman, A. and Birner, T.: Insights on tropical tropopause layer processes using global models, J. Geophys. Res., 112, D23104, doi:10.1029/2007JD008945, 2007.

Gettelman, A., Randel, W. J., Wu, F., and Massie, S. T.: Transport of water vapor in the tropical tropopause layer, Geophys. Res. Lett., 29, 1009, doi:10.1029/2001GL013818, 2002.

Grosvenor, D. P., Choularton, T. W., Coe, H., and Held, G.: A study of the effect of overshooting deep convection on the water content of the TTL and lower stratosphere from Cloud Resolving Model simulations, Atmos. Chem. Phys., 7, 4977-5002, doi:10.5194/acp-7-4977-2007, 2007.

Hanisco, T. F., Moyer, E. J., Weinstock, E. M., St. Clair, J. M., Sayres, D. S., Smith, J. B., Lockwood, R., Anderson, J. G., Dessler, A. E., Keutsch, F. N., Spackman, J. R., Read, W. G., and Bui, T. P.: Observations of deep convective influence on stratospheric water vapor and its isotopic composition, Geophys. Res. Lett., 34, L04814, doi:10.1029/2006GL027899, 2007.

Heyes, W. J., Vaughan, G., Allen, G., Volz-Thomas, A., Pätz, H.W., and Busen, R.: Composition of the TTL over Darwin: local mixing or long-range transport?, Atmos. Chem. Phys., 9, 77257736, doi:10.5194/acp-9-7725-2009, 2009.

Holton, J. R. and Gettelman, A.: Horizontal transport and the dehydration of the stratosphere, Geophys. Res. Lett., 28, 2799-2802, doi:10.1029/2001GL013148, 2001.

Jensen, E. J., Ackerman, A. S., and Smith, J. A.: Can overshooting convection dehydrate the tropical tropopause layer?, J. Geophys. Res., 112, D11209, doi:10.1029/2006JD007943, 2007.

Khaykin, S., Pommereau, J.-P., Korshunov, L., Yushkov, V., Nielsen, J., Larsen, N., Christensen, T., Garnier, A., Lukyanov, A., and Williams, E.: Hydration of the lower stratosphere by ice crystal geysers over land convective systems, Atmos. Chem. Phys., 9, 2275-2287, doi:10.5194/acp-9-2275-2009, 2009.

Knievel, J. C., Bryan, G. H., Copeland, J. H., and Hacker, J. P.: The WRF Model's new explicit numerical diffusion and its effects on transport and dispersion in the planetary boundary layers, American Meteorological Society, New Orleans, Louisiana, http://ams.confex.com/ams/pdfpapers/132741.pdf, 2008.

Lane, T. P. and Sharman, R. D.: Gravity wave breaking, secondary wave generation, and mixing above deep convection in a threedimensional cloud model, Geophys. Res. Lett., 33, L23813, doi:10.1029/2006GL027988, 2006.

Lane, T. P., Sharman, R. D., Clark, T. L., and Hsu, H.-M.: An investigation of turbulence generation mechanisms above deep convection, J. Atmos. Sci., 60, 1297-1321, 2003.

Liu, C. and Zipser, E. J.: Global distribution of convection penetrating the tropical tropopause, J. Geophys. Res., 110, D23104, doi:10.1029/2005JD006063, 2005.

Luderer, G., Trentmann, J., Hungershöfer, K., Herzog, M., Fromm, M., and Andreae, M. O.: Small-scale mixing processes enhancing troposphere-to-stratosphere transport by pyro-cumulonimbus storms, Atmos. Chem. Phys., 7, 5945-5957, doi:10.5194/acp-75945-2007, 2007.

May, P. T., Mather, J. H., Vaughan, G., Jakob, C., McFarquhar, G. M., Bower, K. N., and Mace, G. G.: The Tropical Warm Pool International Cloud Experiment, B. Am. Meteorol. Soc., 89, 629-645, doi:10.1175/BAMS-89-5-629, 2008.

Moyer, E. J., Irion, F. W., Yung, Y. L., and Gunson, M. R.: ATMOS stratospheric deuterated water and implications for tropospherestratosphere transport, Geophys. Res. Lett., 23, 2385-2388, 1996.

Murphy, D. M. and Koop, T.: Review of the vapour pressures of ice and supercooled water for atmospheric applications, Q. J. Roy. Meteor. Soc., 131, 1539-1565, 2005.

Rossow, W. B. and Pearl, C.: 22-Year survey of tropical convection penetrating into the lower stratosphere, Geophys. Res. Lett., 34, L04803, doi:10.1029/2006GL028635, 2007.

Peter, T.: Upscaling results from Hector measurements to global convective $\mathrm{H} 2 \mathrm{O}$ input into the tropical stratosphere. Presented at the SCOUT-O3/ACTIVE/TWP-ICE workshop on the tropical UTLS, University Of Manchester, 8-11 January 2008. http://www.ozone-sec.ch.cam.ac.uk/scout_o3/meetings/ manchester/presentations/Peter.pdf, 2008.

Russell, P. B., Pfister, L., and Selkirk, H. B.: The tropical experiment of the Stratosphere-Troposphere Exchange Project (STEP): science objectives, operations, and summary findings, J. Geophys. Res., 98, 8563-8589, 1993.

Schiller, C., Grooß, J.-U., Konopka, P., Plöger, F., Silva dos Santos, F. H., and Spelten, N.: Hydration and dehydration at the tropical tropopause, Atmos. Chem. Phys., 9, 9647-9660, doi:10.5194/acp-9-9647-2009, 2009.

Schmetz, J., Tjemkes, S. A., Gube, M., and VandeBerg, L.: Monitoring deep convection and convective overshooting with METEOSAT, Adv. Sp. Res., 19, 433-441, 1997.

Setvák, M., Lindsey, D. T., Rabin, R. M., Wang, P. K., and Demeterová, A.: Indication of water vapor transport into the lower stratosphere above midlatitude convective storms: Meteosat Second Generation satellite observations and radiative transfer model simulations, Atmos. Res., 89, 170-180, 2008.

Sherwood, S. C. and Dessler, A. E.: On the control of stratospheric humidity, Geophys. Res. Lett., 27, 677-680, 2000.

Sherwood, S. C. and Dessler, A. E.: A model for transport across the tropical tropopause, J. Atmos. Sci., 58, 765-779, 2001.

Skamarock, W. C., Klemp, J. B., Dudhia, J., Gill, D. O., Barker, D. M., Wang, W., and Powers, J. G.: A description of the Advanced Research WRF Version 2, NCAR Tech. Note NCAR/TN-468+STR, NCAR, Boulder, CO, USA, 2005.

Smith, J. A., Ackerman, A. S., Jensen, E. J., and Toon, O. B.: Role of deep convection in establishing the isotopic composition of water vapor in the tropical transition layer, Geophys. Res. Lett., 33, L06812, doi:10.1029/2005GL024,078, 2006.

Thompson, G., Field, P. R., Rasmussen, R. M., and Hall, W. D.: Explicit forecasts of winter precipitation using an improved bulk microphysics scheme. Part II: implementation of a new snow parameterization, Mon. Weather Rev., 136, 5095-5115, doi:10.1175/2008MWR2387.1, 2008.

Vaughan, G., Schiller, C., MacKenzie, A. R., Bower, K., Peter, T., Schlager, H., Harris, N. R. P., and May, P. T.: SCOUTO3/ACTIVE high-altitude aircraft measurements around deep tropical convection, B. Am. Meteorol. Soc., 89, 647-662, 2008.

Wang, H., Skamarock, W. C., and Feingold, G.: Evaluation of scalar advection schemes in the advanced research WRF model using large-eddy simulations of aerosol-cloud interactions, Mon. Weather Rev., 137, 2547-2558, 2009a.

Wang, P. K.: Moisture plumes above thunderstorm anvils and their contributions to cross-tropopause transport of water vapour in midlatitudes, J. Geophys. Res., 108, 
doi:10.1029/2002JD002581, 2003.

Wang, P. K.: A cloud model interpretation of jumping cirrus above storm top, Geophys. Res. Lett., 31, L18106, doi:10.1029/2004GL020787, 2004.

Wang, P. K.: The thermodynamic structure atop a penetrating convective thunderstorm, Atmos. Res., 83, 254-262, doi:10.1016/j.atmosres.2005.08.010, 2007.

Wang, P. K., Setvák, M., Lyons, W., Schmid, W., and Lin, H.-M.: Further evidences of deep convective vertical transport of water vapor through the tropopause, Atmos. Res., 94, 400-408, $2009 \mathrm{~b}$.
Wu, D. L., Read, W. G., Dessler, A. E., Sherwood, S. C., and Jiang, J. H.: UARS/MLS cloud ice measurements: implications for $\mathrm{H}_{2} \mathrm{O}$ transport near the tropopause, J. Atmos. Sci., 62, 518530, 2005.

Zipser, E. J., Cecil, D. J., Liu, C., Nesbitt, S. W., and Yorty, D. P.: Where are the most intense thunderstoms on Earth? B. Am. Meteorol. Soc., 87, 1057-1071, 2006. 